\title{
Determination of Best Tropopause Definition for Convective Transport Studies
}

\author{
EMILY M. MADDOX AND GRETCHEN L. MULLENDORE \\ Department of Atmospheric Sciences, University of North Dakota, Grand Forks, North Dakota
}

(Manuscript received 26 March 2018, in final form 23 July 2018)

\begin{abstract}
An idealized three-dimensional cloud-resolving model is used to investigate the sensitivity of crosstropopause convective mass transport to tropopause definition. A simulation is conducted to encompass the growth and decay cycle of a supercell thunderstorm, with a focus on irreversible transport above the tropopause. Five previously published tropopause definitions are evaluated: World Meteorological Organization (WMO) temperature lapse rate, potential vorticity, static stability, vertical curvature of the Brunt-Väisälä frequency, and stratospheric tracer concentration. By analyzing the behavior of different definitions both during and after active convection, we are able to define "best" choices for tropopause definitions as those that return to states most closely matching the preconvective environment. Potential vorticity and stratospheric tracer concentration are shown to perform poorly when analyzing deep convection. The WMO thermal tropopause and static stability definitions are found to perform the best, providing similar tropopause placement and quantities of irreversible mass transport. This investigation highlights the challenges of defining a tropopause in the vicinity of deep convection and demonstrates the need to clearly communicate calculation methods and threshold choices in the literature.
\end{abstract}

\section{Introduction}

The chemical budget and radiative balance in the upper troposphere and lower stratosphere (UTLS) are greatly influenced by the transport of chemical constituents to this region from the boundary layer (Dickerson et al. 1987; Hauf et al. 1995; Santer et al. 2003; Skamarock et al. 2000; Twohy et al. 2002). These chemical constituents include greenhouse gases such as water vapor, carbon dioxide, and ozone. Although large-scale stratosphere-troposphere exchange (STE) is understood fairly well, small-scale transport, such as that occurring through deep convection, has not been thoroughly examined. Deep convection is important to STE because it efficiently transports tracers from the boundary layer to the stratosphere (Dickerson et al. 1987; Feichter and Crutzen 1990; Fischer et al. 2003; Hauf et al. 1995; Poulida et al. 1996). This efficient transport can result in high concentrations of species normally not found in the stratosphere, for example, short-lived species that strongly deplete ozone (Wales et al. 2018). These boundary layer tracers can be deposited in the lower stratosphere if heated enough to become neutrally buoyant. This heating can occur through a variety of methods,

Corresponding author: Gretchen L. Mullendore, gretchen@ atmos.und.edu such as latent heating of an air parcel and turbulent mixing at the cloud top (Mullendore et al. 2005). While direct injection of undiluted boundary layer air into the tropical stratosphere is relatively infrequent, this is a common occurrence in midlatitude convection (e.g., Bigelbach et al. 2014; Cooney et al. 2018). To further understand STE, we must be able to quantify tropopause structure and variability (Randel et al. 2007). However, to quantify the tropopause structure and variability, we must have an appropriate tropopause definition. For example, an incorrect tropopause placement could result in an overestimate or underestimate of mass transport from the troposphere to the lower stratosphere.

One could also argue that the tropopause has no definition in the vicinity of deep convection. Deep convection represents a mixing event, and to draw a specific boundary location in the midst of any mixing event is not meaningful. A better approach is to wait until the mixing event has ended and then assess irreversible transport across the boundary. We follow that strategy here by simulating the storm environment well past storm dissipation [the same approach as in Mullendore et al. (2005)]. However, many of our observations of convective transport are only available instantaneously at the time of mixing when the tropopause is ill defined. Additionally, outflow plumes mix with plumes from other storms in the environment 
(as well as with long-range chemical plumes), and source attribution can be difficult away from active convection. It is therefore useful to have agreed-upon definitions for estimating tropopause locations under those conditions. Studies can then present results relative to estimated tropopause altitude (e.g., Bigelbach et al. 2014; Cooney et al. 2018). We will therefore assess the tropopause definition both during active convection and postconvection in this study.

Several tropopause definitions exist in the literature, including temperature lapse rate, potential vorticity, static stability, and tracer chemicals. While the definitions analyzed in this study are discussed in more detail in section 2 and the appendix, a brief description of these categories is given here. Temperature lapse-rate tropopause definitions include the World Meteorological Organization (WMO) thermal tropopause (WMO 1957). Potential vorticity (PV) tropopause definitions are generally applied only to the extratropics and on synoptic scales (Gettelman et al. 2011). Static stability definitions include a single-value threshold (Mullendore et al. 2005) and the maximum vertical curvature of the Brunt-Väisälä frequency (BVF; Birner 2010). Last, trace-gas tropopause definitions, also known as chemical tropopauses, include ozone lapse rates and tracer chemicals (Bethan et al. 1996; Zahn and Brenninkmeijer 2003; Pan et al. 2004).

This study analyzes the sensitivities of mass transport to tropopause definition in a simulated midlatitude supercell storm in a controlled environment. The tropopause definitions used in this study are described in section 2 . Section 3 provides a description of the model setup and simulation overview. The transport results of the simulation are discussed in section 4. Tropopause calculation methods and equations are provided in the appendix.

\section{Tropopause definitions}

To be able to quantify the irreversible transport of boundary layer tracers to the lower stratosphere, the tropopause must be mathematically defined. Typically, the tropopause definition is chosen to fit the study, with most studies investigating at most two tropopause definitions. In this section, an overview of each definition is provided. Additional details on the calculation method and equations used for each definition are provided in the appendix. Note that constant altitude is not dynamically meaningful and is not recommended for use in transport studies. It is only provided in this study for reference.

\section{a. WMO tropopause}

The WMO thermal tropopause definition uses two general criteria that must both be met (WMO 1957, p. 136).
The tropopause is defined as "the lowest level at which the lapse rate decreases to $2^{\circ} \mathrm{C} \mathrm{km}^{-1}$ or less, provided also the average lapse rate between this level and all higher levels within $2 \mathrm{~km}$ does not exceed $2^{\circ} \mathrm{Ckm}^{-1}$, (i.e., the temperature decreases by $2^{\circ} \mathrm{km}^{-1}$ or less). The WMO thermal tropopause definition was the first definition used to identify the tropopause and remains in wide usage because similar thermal structures are observed at all latitudes. However, the definition is worded such that multiple interpretations can be made on the proper way to calculate the tropopause height. The first interpretation used in this study uses the lapse rate of the altitude pairs within $2 \mathrm{~km}$ of the tropopause height. In other words, for the 100-m vertical resolution used in this study, 20 lapse rates are calculated. The second interpretation used in this study (simplified WMO) uses only the local lapse rate and the $2-\mathrm{km}$ average.

\section{b. PV tropopause}

The potential vorticity dynamical tropopause definition, a common definition for synoptic-scale events or climatological studies in the extratropics, uses a subjectively chosen threshold value to determine the tropopause height (Gettelman et al. 2011). The definition requires three-dimensional temperature and wind data, making it effective at determining the tropopause height in global models. The definition uses both static stability and vorticity (Gettelman et al. 2011; Kunz et al. 2011). $\mathrm{PV}$ is a conserved quantity for adiabatic, frictionless flow (Holton and Hakim 2013). Under such conditions, the sharp gradient in PV at the tropopause provides a useful dynamical definition.

When performing synoptic-scale studies, a 2 potential vorticity unit (PVU; 1 PVU $=10^{-6} \mathrm{~K} \mathrm{~kg}^{-1} \mathrm{~m}^{2} \mathrm{~s}^{-1}$ ) surface is often chosen to represent the tropopause (Kunz et al. 2011). However, this value is subject to change based on the study as the PVU surface should be chosen to represent the WMO thermal tropopause or known chemical transition. For example, Hoerling et al. (1991) found that a 3.5-PVU isoline was optimal for their tropopause analysis because it statistically agreed with the thermal tropopause. Kunz et al. (2011) found a seasonal variation between 1.5 and 5 PVU in both the Southern and Northern Hemispheres, with higher values during the summer and lower values during the winter. Although large variations in PVU values were found throughout the year, they agreed that overall a 2-PVU isoline represented the dynamical tropopause well.

\section{c. Static stability tropopause}

When analyzing mass transport, the stability of air parcels plays a vital role. In convective transport, the surface air parcels are transported to the UTLS and, 
unless heated, are negatively buoyant at those altitudes. The parcels must undergo heating processes to make them neutrally buoyant in the UTLS, creating irreversible transport. As stated earlier, these processes can include latent heating, which is the dominant heating mechanism in the updraft, and turbulent mixing at the cloud top, which heats the parcel to remain neutrally buoyant [e.g., see Fig. 9 in Mullendore et al. (2005)].

The static stability tropopause is defined using the vertical gradient in potential temperature, where it is assumed $\partial \theta / \partial z=\Delta \theta / \Delta z$ in this study. This term is a multiplicative factor contributing to $\mathrm{PV}$, the last term in Eq. (A2) in the appendix. Similar to how the temperature lapse rate shows a distinct change between the troposphere and stratosphere, the potential temperature lapse rate also has a distinct change between the two layers. The troposphere is less stable than the stratosphere, where potential temperature increases faster with height. In this study, the average potential temperature lapse rate in the troposphere was $0.003 \mathrm{~K} \mathrm{~m}^{-1}$, and the average $\mathrm{BVF}$ [Eq. (A3)] was $0.01 \mathrm{~s}^{-1}$, while the average potential temperature lapse rate in the stratosphere was $0.018 \mathrm{~K} \mathrm{~m}^{-1}$, and the average BVF was $0.02 \mathrm{~s}^{-1}$.

The static stability definition uses a single value that is most representative of the constant-altitude tropopause in the preconvective environment. Mullendore et al. (2005) states that air irreversibly transported across a boundary with a strong stability gradient will likely remain lofted long enough to undergo mesoscale mixing. In other words, parcels that cross the boundary into the lower stratosphere and are neutrally buoyant in the more stable layer are likely to remain in the lower stratosphere. These parcels remain in the more stable layer long enough for mesoscale mixing events to mix out the tracer plume, leading to complete mixing with lower stratosphere concentrations. In this study, a stability threshold value of $0.012 \mathrm{~K} \mathrm{~m}^{-1}$ was used. However, the threshold value is specific to each convective event simulated. For example, Mullendore et al. (2005) used a threshold of $0.00935 \mathrm{~K} \mathrm{~m}^{-1}$ to represent the tropopause.

\section{d. $C B V F$ tropopause}

The curvature of the BVF (CBVF) tropopause definition defines the tropopause through the curvature of the static stability in a column. The troposphere and stratosphere can be characterized by differences in their static stability, with the stratosphere being more stable. For an unperturbed atmosphere, Birner (2010) states that using the maximum vertical curvature of the BVF produces similar results to the standard WMO definition in the extratropics. It should be noted that this definition was intended for climate studies, not convection. This definition was included because when evaluating mass transport, the stability of an air parcel determines where it remains after convection has dissipated. Unlike the static stability tropopause definition, this definition uses the maximum curvature of static stability.

\section{e. Stratospheric tracer tropopause}

The stratospheric tracer tropopause, also known as a chemical tropopause, is defined using a trace gas that has a strong stratosphere-troposphere gradient (Bethan et al. 1996; Pan et al. 2004; Zahn and Brenninkmeijer 2003). The ozone mixing ratio is commonly used for the chemical tropopause, but determining the proper threshold value to use can be challenging. Some studies, such as Zahn et al. (2004), use multiple trace gases with sources in both the troposphere and stratosphere to determine the tropopause. In their study, ozone, which has higher concentrations in the stratosphere, and carbon monoxide, which has higher concentrations in the troposphere, were used to determine the tropopause height from in situ measurements. In this study, a passive tracer, initially defined only in the stratosphere, was used. An altitude was required to contain at least $50 \%$ stratospheric tracer to be considered as being in the stratosphere.

\section{Simulation description}

\section{a. Model initialization}

This study used a three-dimensional cloud-resolving mesoscale model based on that of Durran and Klemp (1983) and was run using Extreme Science and Engineering Discovery Environment (XSEDE) resources (Towns et al. 2014). The model used $f$-plane approximation and assumed a latitude of $37^{\circ} \mathrm{N}$. As the simulation length was less than typical radiative time scales (i.e., less than $12 \mathrm{~h}$ ), radiation was neglected in the simulation to save computational expense. There was an open vertical boundary and open lateral boundaries, making the only physical boundary the ground. The domain was $750 \mathrm{~km}$ by $475 \mathrm{~km}$ by $19.85 \mathrm{~km}$ (Fig. 1); had horizontal and vertical grid spacings of $1 \mathrm{~km}$ and $100 \mathrm{~m}$, respectively; and had a time step of $1 \mathrm{~s}$. To minimize impacts of imperfect boundary conditions, the analysis domain is defined as $15 \mathrm{~km}$ from the horizontal boundaries and $1.85 \mathrm{~km}$ from the model top.

This study was designed to analyze transport from an isolated cell. To reduce the available potential energy, an area of dry boundary layer air was added to the domain, which suppressed the continuous growth of new convection (see also Mullendore et al. 2005). A 30-km transition zone, beginning at $160 \mathrm{~km}$, was placed between the moist boundary layer air (to the left, or west) 


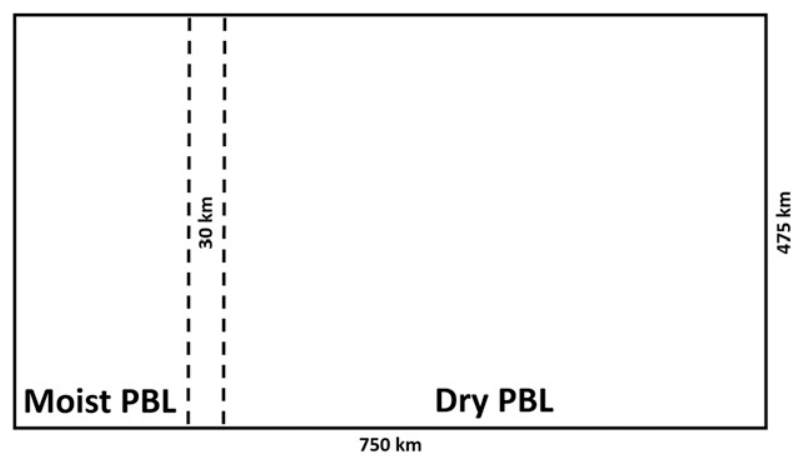

FIG. 1. The domain used for the storm simulation. A moist boundary layer is located to the left (west) of the dashed lines, and a dry boundary layer is located to the right (east) of the dashed lines.

and the dry boundary layer air (to the right, or east), shown in Fig. 1. In the transition zone, water vapor decreased linearly with $x$.

A single sounding was used to initialize the model. The potential temperature $\bar{\theta}$ was given by

$$
\overline{\theta(z)}=\left\{\begin{array}{lll}
\theta_{0}+\left(\theta_{\mathrm{tr}}-\theta_{0}\right)\left(\frac{z}{z_{\mathrm{tr}}}\right)^{5 / 4} & \text { for } & z \leq z_{\mathrm{tr}} \\
\theta_{\mathrm{tr}} \exp \left[\frac{g}{c_{p} T_{\mathrm{tr}}}\left(z-z_{\mathrm{tr}}\right)\right] & \text { for } & z>z_{\mathrm{tr}}
\end{array},\right.
$$

where $\theta_{0}$ is the potential temperature at the surface $(301.4 \mathrm{~K}), \theta_{\text {tr }}$ is the potential temperature at the tropopause $(337.6 \mathrm{~K}), z_{\text {tr }}$ is the tropopause height $(10.85 \mathrm{~km})$, $c_{p}$ is the specific heat of dry air, and $T_{\text {tr }}$ is the temperature at the tropopause $(223.0 \mathrm{~K}$; Weisman and Klemp 1982). The sounding was isothermal above the tropopause. Wind shear in the lowest $5 \mathrm{~km}$ was modeled off of the idealized supercell case in Mullendore et al. (2005). The water vapor profile was also as given in Weisman and Klemp (1982) but was adjusted such that water vapor decreased to $0 \mathrm{~g} \mathrm{~kg}^{-1}$ from $9.85 \mathrm{~km}$ to the model top. The original cell was initialized in the moist section of the domain using an instantaneous thermal bubble centered at $1.4-\mathrm{km}$ altitude with dimensions $10 \mathrm{~km}$ by $10 \mathrm{~km}$ by $1.4 \mathrm{~km}$. The bubble had a $2-\mathrm{K}$ perturbation above the environmental temperature. While this storm initialization method is artificial, the resulting convection already exhibits characteristics different from the initial bubble at $15 \mathrm{~min}$ into the simulation. As the updraft is weak during that initial spinup period, it is unlikely this artificial initialization method had significant impacts on the transport results.

A main goal of this study was to quantify the sensitivity of cross-tropopause transport to the tropopause definition. To investigate how mass was transported during the convective event, passive tracers were used.
These tracers were simulated using a flux-limited advection scheme (Skamarock 2006). Passive tracers, which had an initial value of 1.0 , were initially confined within horizontally homogeneous layers, with all areas outside of the layer being zero. The boundary layer tracer was confined from 0.1 to $1.45 \mathrm{~km}$. The stratospheric tracer was defined from 10.85 to $19.85 \mathrm{~km}$ (model top) and was used as a tropopause definition. Since the focus of this study was to determine the sensitivity of irreversible boundary layer tracer transport to tropopause definition, the stratospheric tracer was only evaluated as a tropopause definition and was not evaluated for downward transport into the troposphere.

\section{b. Overview of simulated case}

A single updraft cell was present $30 \mathrm{~min}$ into the simulation, which reached a height of $11.7 \mathrm{~km}$ with a maximum vertical velocity of $36 \mathrm{~m} \mathrm{~s}^{-1}$. The updraft strength surpassed $50 \mathrm{~m} \mathrm{~s}^{-1}$ at a simulation time of approximately $40 \mathrm{~min}$ and remained that strong until approximately $1 \mathrm{~h} 10 \mathrm{~min}$, shown in Fig. 2 . The eastern edge of the main cell reached the dry boundary layer air region at a simulation time of approximately $45 \mathrm{~min}$, and the storm began to dissipate at that time. All convection had dissipated by approximately $4.5 \mathrm{~h}$, and the isentropes became relaxed.

Before describing the analysis of the primary storm complex, tracer contamination from additional convection is removed. Additional convection remained present in the domain throughout the simulation, even with the inclusion of the dry boundary layer air region. Cells that developed in response to the initial temperature perturbation were investigated, referred to here as the analysis storm system. Additional convection that began at approximately $2.75 \mathrm{~h}$ was not investigated. All convection that was not associated with the analysis storm system was masked out. In other words, columns of the domain associated with the additional convection were not included in mass transport calculations. For example, Fig. 3 depicts all convection present throughout the domain at $3.0 \mathrm{~h}$. The cells highlighted by the red box are cells that were masked out or not included in the analysis. In the masking process, the boundary layer tracer transport to the UTLS region was analyzed every $200 \mathrm{~m}$ in the vertical from 9.85 to $12.85 \mathrm{~km}$ to ensure tracer transport from additional convection did not merge with the analysis storm system. At $3.0 \mathrm{~h}$, tracers transported by the analysis storm complex and the additional convection remained separated. After $6.75 \mathrm{~h}$, boundary layer tracer lofted by the additional convection began to merge with the analysis cell. Therefore, $6.75 \mathrm{~h}$ will be used to analyze the postconvective state. 


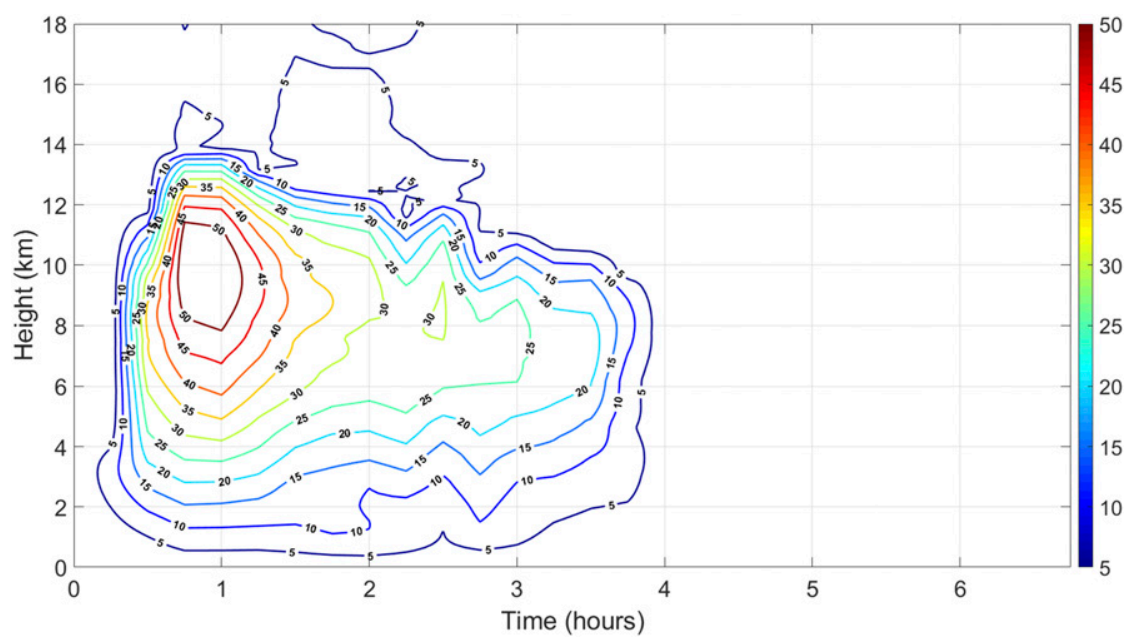

FIG. 2. A time-height plot of the maximum vertical velocity at each vertical level throughout the simulation in the analysis domain.

Two times were chosen for analysis in this study: $1 \mathrm{~h}$, or the state of active convection, and $6.75 \mathrm{~h}$, or the state of postconvection. These times were chosen to evaluate the fluctuations in tropopause height as well as changes in mass transport between the active convective environment and postconvective environment. Although significant tracer exists at (and above) $10.85 \mathrm{~km}$ at $1.0 \mathrm{~h}$, because parcels may be negatively buoyant, there is no confidence in irreversible transport until $6.75 \mathrm{~h}$. Figure 4 depicts the boundary layer tracer present at the constantaltitude tropopause at $6.75 \mathrm{~h}$, showing irreversible transport has occurred. To further show the storm evolution, Fig. 5 shows vertical cross sections of the boundary layer tracer at three times: 0 (the preconvective environment), 1 (the active convective environment), and $6.75 \mathrm{~h}$ (the postconvective environment). Again, it is clear when looking at the vertical cross section at $6.75 \mathrm{~h}$ that irreversible transport has occurred from the boundary layer to the lower stratosphere as the atmosphere is no longer perturbed by instabilities (i.e., potential temperature lines are flat).

\section{Results}

To investigate irreversible transport, the focus on mass transport quantities should be put on the postconvective environment. Large quantities of boundary layer tracers are transported above the constant-altitude tropopause during the convective event (Fig. 6), but many of these boundary layer parcels are negatively buoyant and do not remain at stratospheric altitudes. Parcels analyzed in the postconvective environment (Fig. 4) are neutrally buoyant at stratospheric altitudes, showing irreversible transport. However, as discussed in the introduction, many studies need to present tropopause-relative results, even during active convection. To investigate the tropopause definitions, this subsequent analysis will focus on the UTLS region $(10-15 \mathrm{~km})$.

\section{a. Tropopause evolution}

To investigate the tropopause region during active convection, the output at $1.0 \mathrm{~h}$ was evaluated, shown in Fig. 7a. As stated previously, PV and CBVF are applicable at synoptic temporal and spatial scales and generally not chosen for tropopause identification in convective cases. Figure $7 \mathrm{a}$ clearly demonstrates the weaknesses of these two tropopause definitions in active convection. The PV definition (red line) shows strong perturbations at the convective scale, extending from the surface to the model top in the updraft regions (not shown). The CBVF (cyan line) also shows several perturbations in the tropopause but not to the extent of the PV definition. Most of the CBVF perturbations occurred in the anvil regions of the cell. The stratospheric tracer definition (green line) placed the tropopause a few hundred meters higher than the remaining definitions. As expected, the definition followed the upper boundary of the $25 \%-50 \%$ boundary layer tracer. Recall that an altitude must contain at least $50 \%$ stratospheric air to be considered in the stratosphere when using this definition.

Finally, the WMO (orange and dark blue lines) and static stability (magenta line) definitions were in approximate agreement on the tropopause location. It is difficult to distinguish the WMO and static stability definitions in Fig. 7 as the definitions often placed the tropopause at the same altitude. The only location of disagreement in tropopause placement was between the updraft and downdraft regions (Fig. 7a; around $125 \mathrm{~km}$ in the $x$ direction), and a small disagreement in tropopause location (100-m 


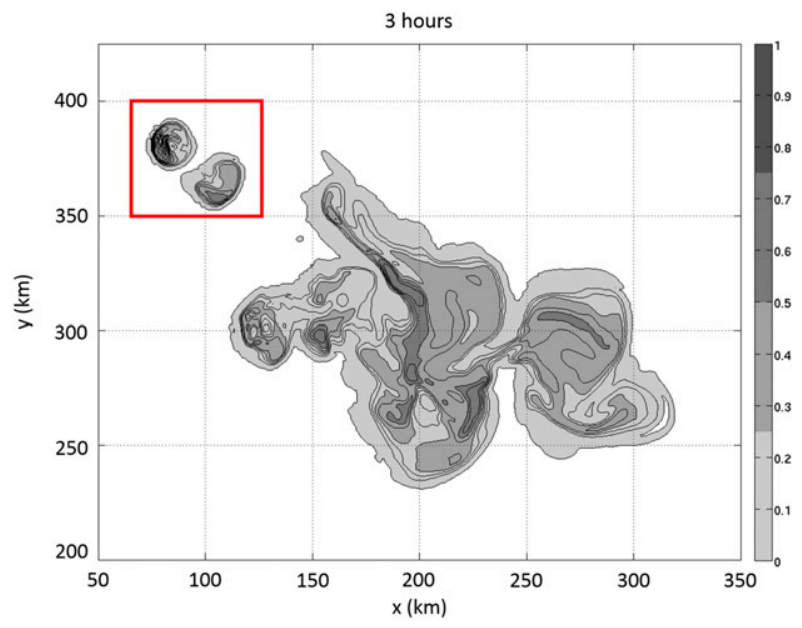

FIG. 3. A horizontal cross section depicting the boundary layer tracer at the constant-altitude tropopause, $10.85 \mathrm{~km}$, at $3 \mathrm{~h}$. The gray-scale contours represent the boundary layer tracer with a contour interval of $0.01 \mathrm{~kg} \mathrm{~kg}^{-1}$. The red box outlines additional convection that was not included in the analysis domain.

difference) at the peak of the updraft. Moving into the anvil region of the storm, the tropopause definitions were more consistent. The similar behavior in tropopause placement of the WMO and static stability definitions was expected as the location of the sharp change in temperature lapse rate (WMO) is perturbed in the same way as the location of the sharp change in static stability. Note that while this outcome suggests that the CBVF definition should also perform well, the CBVF tests maximum curvature instead of first occurrence over a threshold, hence displacing it from the WMO definition.

After convection has dissipated (Fig. 7b), tropopause definitions appropriate for convective environments return to a nearly constant altitude, as the mechanisms driving the deformation have also dissipated. Hence, surfaces with persistent deformation can be deemed inappropriate. At this time, the PV tropopause continued to provide tropopause locations throughout the lower stratosphere. These PV anomalies persisted after all convection had dissipated because no additional synopticscale shearing or mixing events took place in the model. These events include mixing at cloud boundaries, mixing around the subtropical jet, and clear-air turbulence. The processes by which fields such as PV mix to smaller and smaller scales over time through these events, similar to how boundary layer tracer is mixed into the lower stratosphere over time, is discussed in section 2. The CBVF tropopause also continued to be varied in its placement, varying by $100-1000 \mathrm{~m}$ (note that the larger differences in tropopause height are not shown in the selected cross section). The variability in tropopause height resulted in an average tropopause height of $10.69 \mathrm{~km}$,

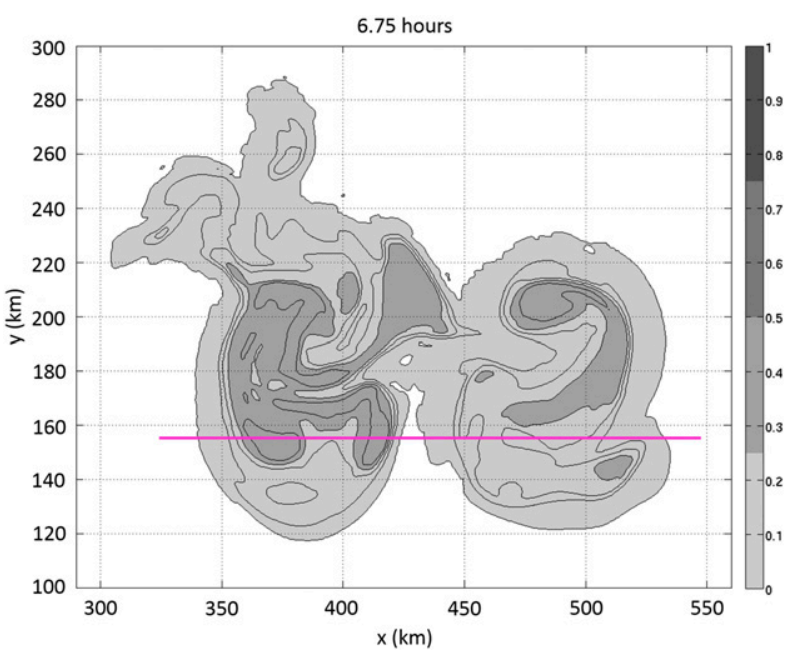

FIG. 4. A horizontal cross section depicting the boundary layer tracer at the constant-altitude tropopause, $10.85 \mathrm{~km}$, at $6.75 \mathrm{~h}$. The gray-scale contours represent the boundary layer tracer with a contour interval of $0.01 \mathrm{~kg} \mathrm{~kg}^{-1}$. To avoid showing small-scale numerical oscillations, the minimum boundary layer concentration depicted is $0.001 \mathrm{~kg} \mathrm{~kg}^{-1}$. The magenta line represents the location of the vertical cross section shown in Fig. 5.

the lowest analysis domain average tropopause. The stratospheric tracer also performed poorly, with placement often $100 \mathrm{~m}$ below the remaining definitions where boundary layer tracer was not present in the UTLS region because of subsidence. Additionally, it was often placed $100-300 \mathrm{~m}$ higher than the remaining definitions in areas with boundary layer tracer present because of the threshold constraint of $50 \%$ stratospheric air discussed above.

Finally, the WMO and static stability definitions were nearly always in agreement in the tropopause location. There were a few instances where the tropopause was placed with a $100-\mathrm{m}$ difference, but overall, the tropopause placement was very similar. The analysis domain average tropopause height of the WMO and static stability tropopause heights increased by 30 and $40 \mathrm{~m}$, respectively, when compared to the initial tropopause height. During a convective event, the UTLS is heated by the thermodynamic processes occurring with the storm. This heating results in areas of increased tropopause height of a few hundred meters in proximity to the convective event.

\section{b. Irreversible mass transport}

To determine the impact of tropopause definition on irreversible mass transport, $6.75 \mathrm{~h}$ was evaluated. As discussed in section 3, all convection in the analysis domain dissipated around $4.5 \mathrm{~h}$. In this study, the best tropopause definition is determined by assessing which definitions return to a preconvective state once the 

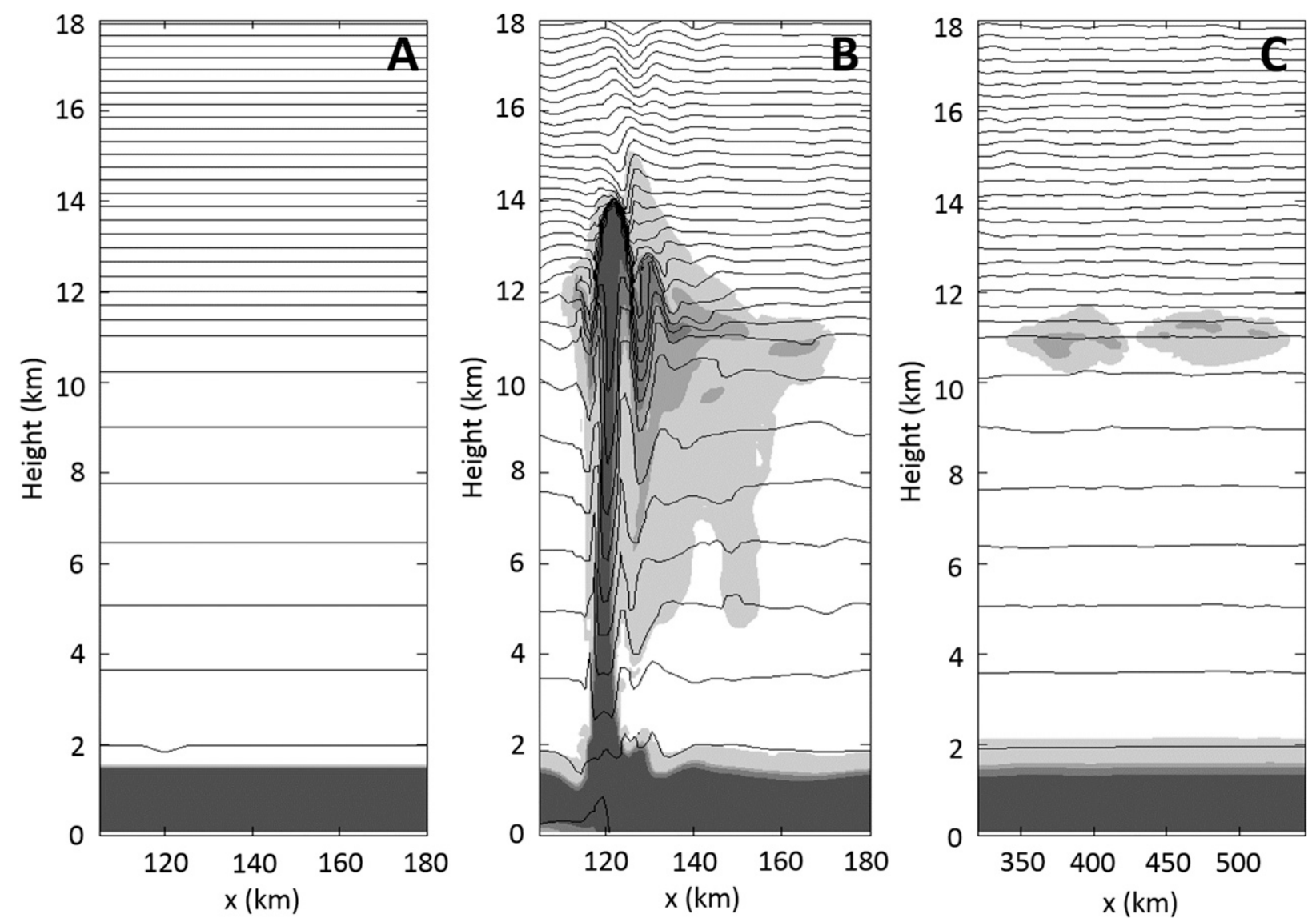

FIG. 5. A vertical cross section (a) at the time of initialization, (b) through the maximum updraft at $1.0 \mathrm{~h}$, and (c) through boundary layer tracer remaining in the UTLS region at $6.75 \mathrm{~h}$. Gray-scale contours represent boundary layer tracer $\left(\mathrm{kg} \mathrm{kg}^{-1}\right)$, with darker shading representing boundary layer concentrations greater than $0.75 \mathrm{~kg} \mathrm{~kg}^{-1}$. To avoid showing small-scale numerical oscillations, the minimum boundary layer concentration depicted is $0.001 \mathrm{~kg} \mathrm{~kg}^{-1}$. Thin black lines represent isentropes from 295 to $500 \mathrm{~K}$ with a $5-\mathrm{K}$ contour interval.

convection has dissipated. In other words, the tropopause is deemed best if it has no discontinuities and returns to a nearly constant altitude after the storm has dissipated. Assessing the environment over $2 \mathrm{~h}$ postconvection indicates which definitions no longer show significant perturbations on a convective time scale. In these calculations, the PV tropopause was not analyzed as it was so inaccurate (particularly during active convection; Fig. 7a) that no tropopause could be defined for mass transport calculations.

For reference, the constant-altitude tropopause resulted in the largest amount of mass transport, approximately $11.1 \times 10^{11} \mathrm{~kg}$ (Fig. 8; exact quantities of mass transported can be found in Table 1). As discussed above, the WMO and static stability definitions placed the tropopause at similar altitudes both during and after the convective events. Quantitatively, their use as the tropospherestratosphere boundary results in similar amounts of mass transport. The WMO and static stability definitions resulted in $5 \%$ and $7 \%$ less mass transport, respectively, than that found when using the constantaltitude tropopause. The average CBVF tropopause height at $6.75 \mathrm{~h}$ was approximately $200 \mathrm{~m}$ below the WMO definitions, which led to an increase in mass transport when using this definition. Using the CBVF definition resulted in $2.5 \%$ less mass transport than the constant altitude. While the mass transport estimation is similar to that of the constant altitude, the tropopause location is discontinuous in several locations. Using the stratospheric tracer definition resulted in $39 \%$ less mass transport than the constant-altitude definition.

Figure 8 shows that using any of the definitions during the active convection gives incorrect mass transport. Even the best definitions overestimate the final transported mass. If one instead chose to define the tropopause using the preconvective environment (in this simulation equal to the constant-altitude definition), the mass transport is also overestimated. Our recommendation for UTLS 


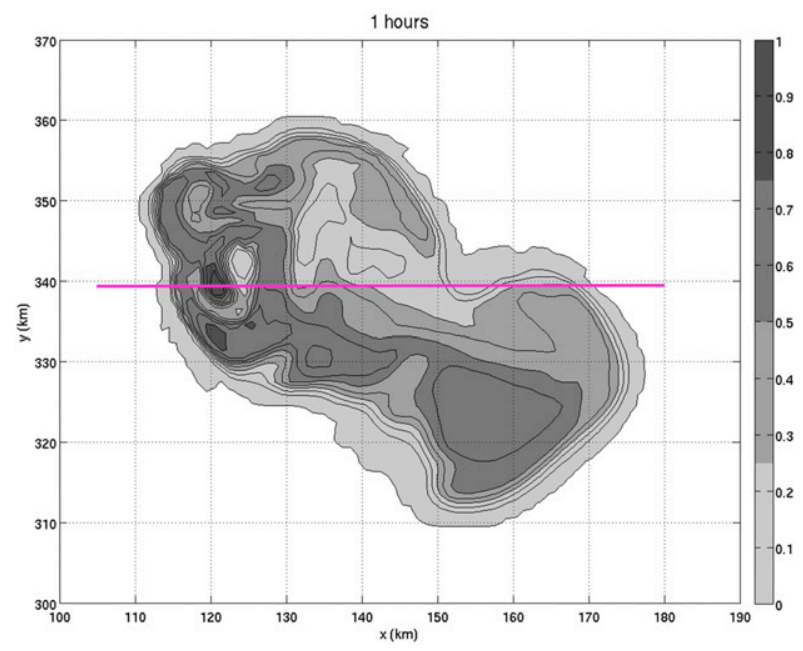

FIG. 6. As in Fig. 4, but at $1 \mathrm{~h}$.

convective studies is to assess the environment in the postconvective state if possible. For active convection analysis, studies can at minimum provide details about tropopause definition calculations and be consistent about tropopause definition chosen such that relative differences in results can be understood even if absolute values contain biases.

\section{c. Discussion of sensitivities}

Tropopause definitions using PV, CBVF, and stratospheric tracer were determined to be inappropriate for analyzing deep convection, while definitions using WMO and static stability were determined to be more suitable. However, dynamic processes are not the only factor that can influence tropopause placement. Additional choices made by the investigator can alter the tropopause placement of each definition, changing the quantity of mass transported above the definition. Here, we investigate three factors: thresholds used, definition interpretations, and regional applicability.

\section{1) THRESHOLDS}

Several definitions in this study used threshold values. However, having to subjectively choose threshold values allows possible error in mass transport calculations. For example, the threshold value chosen for the static
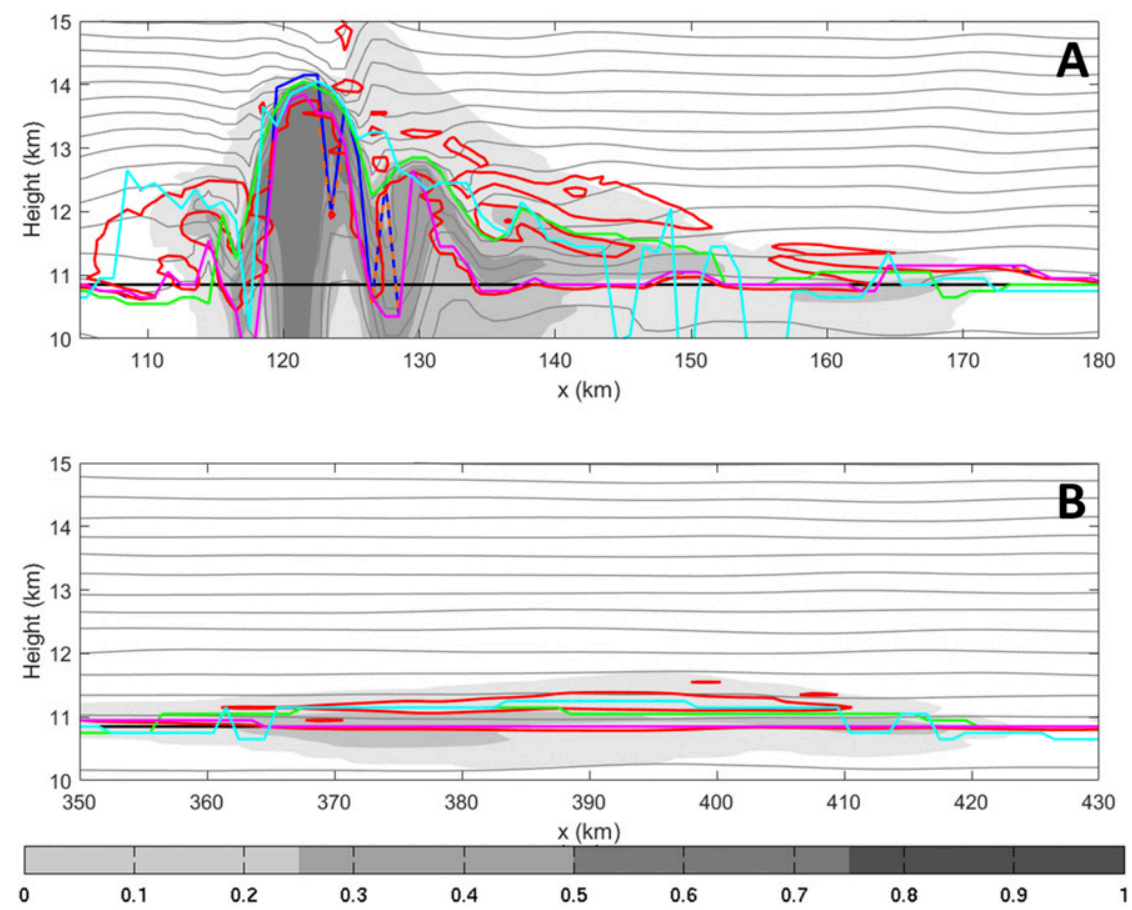

FIG. 7. A vertical cross section at (a) 1.0 and (b) $6.75 \mathrm{~h}$. Gray-scale contours represent boundary layer tracer $\left(\mathrm{kg} \mathrm{kg}^{-1}\right)$, with darker shading representing boundary layer concentrations greater than $0.75 \mathrm{~kg} \mathrm{~kg}^{-1}$. To avoid showing small-scale numerical oscillations, the minimum boundary layer concentration depicted is $0.001 \mathrm{~kg} \mathrm{~kg}^{-1}$. Thin gray lines represent isentropes with a $5-\mathrm{K}$ contour interval. The thick black line represents the constant-altitude tropopause, dark blue represents simplified WMO, dashed orange represents WMO, red represents the PV tropopause, green represents the stratospheric tracer tropopause, magenta represents the static stability tropopause, and cyan represents the CBVF tropopause. 


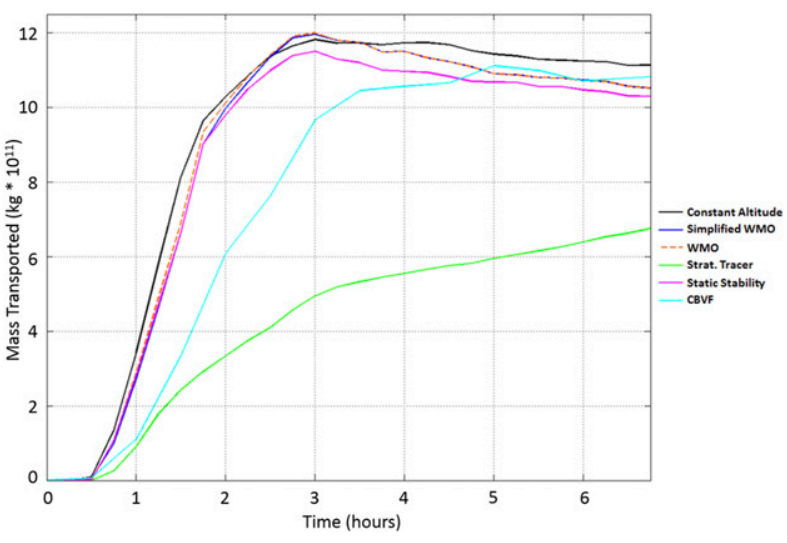

FIG. 8. Mass transported above each tropopause definition is shown. Definitions are constant altitude (black), simplified WMO (dark blue), WMO (orange), stratospheric tracer (green), static stability (magenta), and CBVF (cyan). The PV definition was not considered in this calculation because of its misrepresentation of the tropopause location both during and after convective events.

stability definition in this study was modeled off of the constant-altitude tropopause at the time of initialization. A value of $0.012 \mathrm{~K} \mathrm{~m}^{-1}$ was found to be most representative of the tropopause compared to the value of $0.00935 \mathrm{~K} \mathrm{~m}^{-1}$ used in Mullendore et al. (2005). If the value from Mullendore et al. (2005) had been used, the total mass transported would have increased by $19 \%$. At this time, using the static stability definition requires the user to have knowledge of the preconvective environment, which may be difficult in real-world case studies. Since mass transport is sensitive to the threshold used, it is very important that threshold values are representative of the tropopause height in the unperturbed atmosphere.

A second example of threshold dependence in this study was the stratospheric tracer definition. A threshold of $0.5 \mathrm{~kg} \mathrm{~kg}^{-1}$ was chosen, meaning at least $50 \%$ of the air had to be stratospheric for an altitude to be considered in the stratosphere. However, to the authors' knowledge, there is currently no standard for passive tracer threshold. To test threshold dependence here, the threshold was increased and decreased by $10 \%$ to evaluate the impact on tracer transport. Decreasing the threshold by $10 \%$ resulted in a $15 \%$ increase in mass transport compared to the $0.5 \mathrm{~kg} \mathrm{~kg}^{-1}$ threshold. Increasing the threshold by $10 \%$ resulted in a $21 \%$ decrease in mass transport. These simple fluctuations in threshold values show the importance of clearly communicating the thresholds used in the literature. This challenge of choosing a threshold value is present in all studies that use chemical tracers. When comparing the same tracer between studies, it is vital that they use similar thresholds to be able to accurately compare their results. However, regardless of threshold choice, this definition is a poor choice for determining tropopause height in mass transport studies as it depends solely on a tracer threshold rather than accounting for thermodynamic processes such as latent heating of the air parcel. For example, a parcel of air originating in the boundary layer may be heated enough while being transported through the updraft core to become neutrally buoyant in the lower stratosphere. This parcel may undergo little mixing with stratospheric air. Even though the parcel is now neutrally buoyant in the stratosphere, if it does not undergo enough mixing with stratospheric air, the parcel would still be considered as tropospheric as it does not contain enough stratospheric tracer. This results in an underestimation of mass transport during and after the convective event because the parcels of undiluted boundary layer air are still considered tropospheric regardless of their location.

\section{2) WMO INTERPRETATION}

Section 2 introduced two calculation interpretations of the WMO thermal tropopause definition. Again, the primary WMO definition included the temperature lapse rate of each vertical-level pair within $2 \mathrm{~km}$ of the possible tropopause point. Simplified WMO included only the $2-\mathrm{km}$ vertical average, a simplified version of the WMO, representative of coarse models. Shown in Table 1, both interpretations provide the same amount of mass transported after convection has dissipated. However, during the convective event, the two interpretations provide differing placement of the tropopause, resulting in differing amounts of mass transported. At $1.0 \mathrm{~h}$, WMO transported $15 \%$ less mass than the constant-altitude tropopause and simplified WMO, 21\% less mass.

We recommend use of the WMO calculation that uses all vertical levels as it is more reflective of the original WMO definition and is already used by transport studies (e.g., Homeyer et al. 2014). However, the original definition was published at a time when the resolution of the thermodynamic data was fairly coarse. This definition requires calculating the gradients between the tropopause level and every level above a 2-km altitude range. A sharp gradient in temperature near the tropopause level is calculated directly (e.g., $\Delta T / \Delta z$ ), while a local sharp gradient near the top of the $2-\mathrm{km}$ region will be reduced in magnitude as the gradient is calculated over the whole $2-\mathrm{km}$ altitude range [e.g., $\Delta T /(10 \Delta z)]$. This results in sharp temperature lapse rates near the tropopause level being weighted more than sharp gradients aloft. Careful application of this definition is recommended in cases where the complex vertical structures are sampled at high resolution. Further research into this issue is needed. 
TABLE 1. For each tropopause definition at $6.75 \mathrm{~h}$, the analysis grid average tropopause height, total mass transported above the tropopause, and absolute and relative difference of mass transport with respect to the constant-altitude tropopause definition (tested definition minus constant-altitude definition). Total mass transported above the tropopause using constant-altitude tropopause definition is $11.1 \times 10^{11} \mathrm{~kg}$.

\begin{tabular}{lcccc}
\hline \hline \multicolumn{1}{c}{ Definition } & $\begin{array}{c}\text { Average tropopause } \\
\text { height }(\mathrm{km})\end{array}$ & $\begin{array}{c}\text { Mass transport } \\
\left(\mathrm{kg} \times 10^{11}\right)\end{array}$ & $\begin{array}{c}\text { Absolute diff } \\
\left(\mathrm{kg} \times 10^{11}\right)\end{array}$ & $\begin{array}{c}\text { Relative } \\
\text { diff }(\%)\end{array}$ \\
\hline WMO & 10.88 & 10.5 & -0.6 & -5 \\
Simplified WMO & 10.88 & 10.5 & -0.6 & -5 \\
Stratospheric tracer & 10.86 & 6.8 & -4.3 & -39 \\
Static stability & 10.89 & 10.3 & -0.8 & -7 \\
CBVF & 10.69 & 10.8 & -0.3 & -2.5 \\
\hline
\end{tabular}

\section{3) RegionAl APPLICABILITY}

Definitions such as the WMO thermal tropopause and static stability tropopause are the best at determining tropopause location for midlatitude convective events, but how universal are they? To determine the universality of these definitions, a simple investigation was performed comparing midlatitude and tropical soundings (Fig. 9). Each sounding was formed using the same environmental potential temperature equation [Eq. (1)] used to initialize the simulation. For the midlatitude case, a surface temperature of $25^{\circ} \mathrm{C}$, tropopause temperature of $-51^{\circ} \mathrm{C}$, and tropopause height of $10.85 \mathrm{~km}$ were used, based off the storm used in this study. For the tropical case, a surface temperature of $29^{\circ} \mathrm{C}$, tropopause temperature of $-82^{\circ} \mathrm{C}$, and tropopause height of $15.5 \mathrm{~km}$ were used, based off a WRF simulation performed by Barber (2015). The soundings in this example were created such that they have nearly identical stability in the stratosphere, as can be seen in Fig. 9. The average stratospheric potential temperature lapse rate was $0.018 \mathrm{~K} \mathrm{~m}^{-1}$ in the midlatitude case and was $0.02 \mathrm{~K} \mathrm{~m}^{-1}$ in the tropical case. The average stratospheric temperature lapse rate was approximately $0.5^{\circ} \mathrm{C} \mathrm{km}^{-1}$ in the midlatitudes case and $1.2^{\circ} \mathrm{C} \mathrm{km}^{-1}$ in the tropical case. Although both stratospheric temperature lapse rates meet the WMO criteria, this simple example shows that profiles with nearly the same stratospheric stability do not necessarily have the same stratospheric temperature lapse rate. Conversely, to make the temperature lapse rate identical for each case, the stability in the stratosphere would then differ more. This shows that lapse rates at specific locations may indicate different levels of stability. Between the midlatitudes and tropics, the tropopause height varies greatly. In this example, the tropopause height differs by approximately $5.3 \mathrm{~km}$. The tropopause height is occurring at different temperatures, clear through Fig. 9, and different pressure levels. Since the strength of stability plays an important role in convective transport, it is worthwhile to note that a fixed temperature lapse rate does not necessarily correspond to a fixed stability threshold (or vice versa).

\section{Summary and conclusions}

A three-dimensional cloud-resolving model was used to analyze the sensitivity of cross-tropopause transport to the tropopause definition. Convection was suppressed around $1 \mathrm{~h}$ as the main cell entered the dry boundary layer region. All convection dissipated around $4.5 \mathrm{~h}$. The supercell was simulated out to $6.75 \mathrm{~h}$ to evaluate irreversible transport of boundary layer air parcels into the lower stratosphere. Air parcels originating in the boundary layer were able to penetrate into the lower stratosphere and, through diabatic processes, were able to become neutrally buoyant at stratospheric altitudes.

Five tropopause definitions were evaluated in this study: WMO, PV, stratospheric tracer, static stability, and vertical CBVF. Irreversible transport from the boundary layer to the lower stratosphere is dependent on tropopause placement as it dictates the lower bound of the stratosphere, making it vital that the tropopause is placed correctly during and after convective events. The tropopause is considered to be best if it has met the criteria of having no discontinuities and returning to a nearly constant altitude after the storm has dissipated. Definitions such as the PV and CBVF tropopause were found to provide unreliable tropopause placements during and after convective cases. The PV definition identified the tropopause from the surface to the model top in the updraft core. Figure 7 clearly shows that PV does not provide a reliable tropopause height in an environment recently perturbed by deep convection and therefore is not recommended for use in deep convective studies. The CBVF definition is also not recommended as it often identified a displaced tropopause, showing unphysical jumps in altitude.

The stratospheric tracer definition required that an altitude contain at least $50 \%$ stratospheric tracer air to be considered as in the stratosphere. This resulted in an overestimation in tropopause height and an underestimation in irreversible mass transport. It was further shown that the stratospheric tracer definition is sensitive to threshold chosen. More importantly, this 

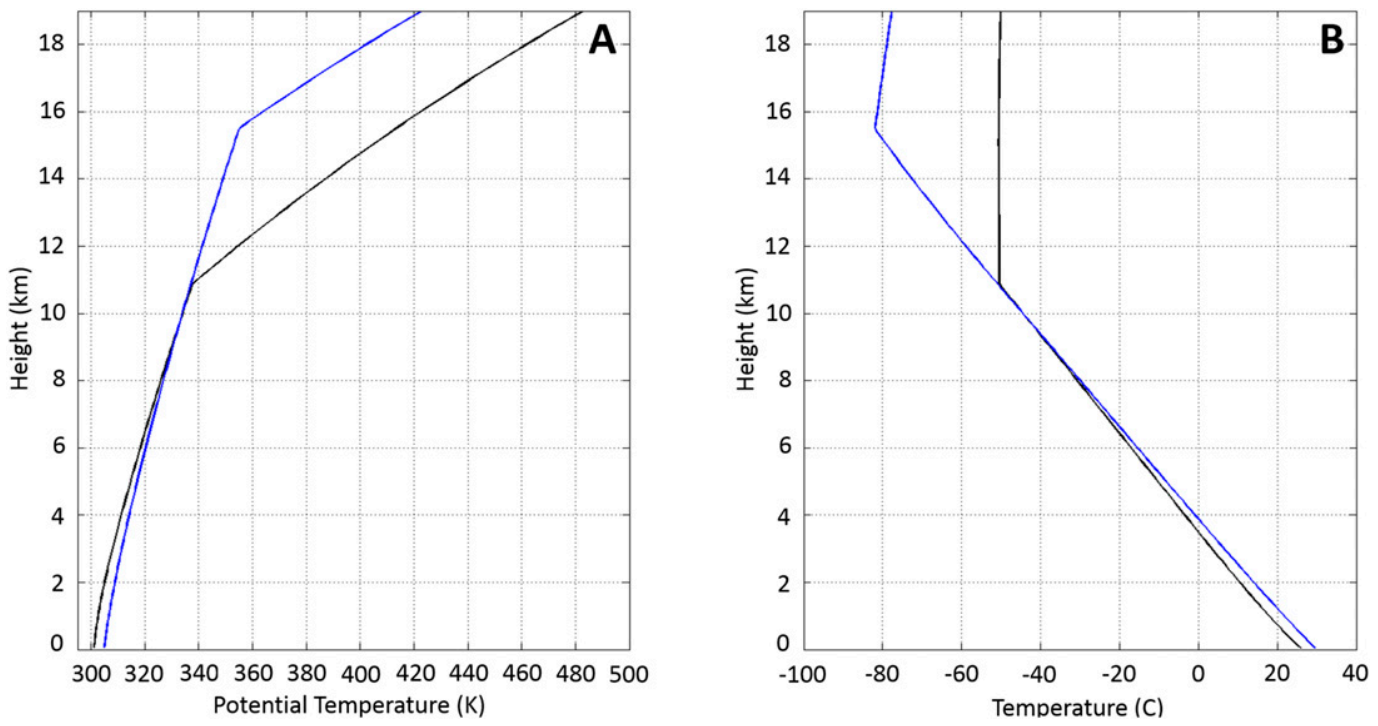

FIG. 9. (a) Potential temperature profile and (b) temperature profile for the midlatitudes (black) and tropics (dark blue).

definition is fundamentally flawed for transport studies, as relatively undiluted boundary layer parcels can be heated sufficiently to be neutrally buoyant in the stratosphere and yet contain very little stratospheric tracer.

The WMO and static stability tropopause definitions placed the tropopause at similar altitudes both near and away from convection. Amounts of mass transported to the stratosphere calculated with these definitions were similar in magnitude. Both WMO interpretations use generalized criteria, described by WMO (1957). The use of these general criteria make the definition applicable in multiple regions because they diagnose altitudes with the same range of temperature lapse rates. In contrast, the static stability method requires the user to identify the proper threshold from the preconvective environment specific to that convective event, making it sensitive to the threshold used. This definition has not been widely used in mass transport studies, but further investigation of typical stability profiles and thresholds at the tropopause heights could be used to create general criteria such as that used by the WMO definition. It is possible that a widely used stability threshold such as BVF (not CBVF) in combination with an average layer criterion (such as that used by the WMO definition) would be sufficient.

From the findings of this study, it is not recommended to use the PV, CBVF, or stratospheric tracer definitions when analyzing deep convection. The WMO and static stability definitions are the best definitions, using the criteria defined earlier in this section, when analyzing convective mass transport. Because the WMO definition can easily be applied to any temperature profile in various regions of the globe without any alterations to criteria, it is the best tropopause definition for convective mass transport at this time. However, process studies of convective transport depend on stability magnitude, so we recommend that gradients of potential temperature be considered in those studies even when the WMO tropopause definition is used.

A possible shortcoming of this study is that only one storm type has been tested. As supercells have the strongest updrafts of all deep convective types, results from other storm types (e.g., mesoscale convective systems) will likely be less dramatic than what is shown here. And while we expect the results to be consistent with this study, it would be valuable to test additional storm types in future studies. It would also be valuable to test more complex environments. For example, when there is insufficient vertical resolution to identify double tropopause structures (Homeyer et al. 2014, see their Fig. 1), the WMO can misidentify the tropopause location [e.g., see Fig. A1 in Sharman and Pearson (2017)].

This study highlights the importance of knowing which definitions are appropriate for deep convective studies. Since there are several definitions published in the literature, it is vital that we discuss their impact on mass transport as a scientific community. Results from studies that use differing tropopause definitions may not be comparable to each other. Additionally, many studies do not clearly state how tropopause definitions were calculated. Many definitions are often worded in a manner that makes them open to varied interpretations, such as the WMO thermal tropopause. It is important for studies to clearly communicate how they are calculating these definitions so that the transport community can 
better work together toward an improved understanding of global stratosphere-troposphere exchange.

Finally, it is important to note the difference in mass transport between active convection and postconvection. It was shown that all definitions performed poorly during active convection; mass transport amounts calculated during active convection were not consistent with the total mass remaining in the lower stratosphere. This was not unexpected as boundaries cannot be determined during active mixing. However, most studies analyze mass transport during active convection because it is difficult to keep tracer plumes isolated (i.e., source attribution challenges) and/or observations are only available during the active convection. We recommend that in studies of active convection, authors clearly communicate tropopause calculation methods used such that relative comparison between results can be made.

Acknowledgments. This research was supported by the National Science Foundation (NSF) under Grant AGS-1432930. This work used the Extreme Science and Engineering Discovery Environment (XSEDE) Comet at the SDSC through Allocation ATM110005; XSEDE is supported by NSF Grant ACI-1548562. We thank Dr. Cameron Homeyer for providing useful discussions throughout many stages in this research. We also thank the three anonymous reviewers for their helpful comments.

\section{APPENDIX}

\section{Tropopause Definitions}

Below is a guide to each of the tropopause calculations used in this study. In all calculations, the differencing function used was first-order forward differencing (FOFD); that is,

$$
\Delta \theta_{i}=\theta_{i+1}-\theta_{i}
$$

is the form used for every variable unless otherwise stated. FOFD is implied in the WMO definition, explained in section 2, and was therefore used for all differencing calculations. It should be noted that interpolation was not used in these calculations. However, the case analyzed here used a standard vertical grid spacing of $100 \mathrm{~m}$.

\section{a. WMO (temperature lapse rate)}

Two interpretations of the definition of the tropopause (see section 2a) were evaluated in this study.

\section{1) $\mathrm{WMO}$}

This interpretation was modeled after the method used in Homeyer et al. (2014). First, the temperature lapse rate, $\Gamma=-\Delta T / \Delta z$, was calculated for every vertical level in the selected profile. The first altitude that had a local lapse rate less than $2 \mathrm{~K} \mathrm{~km}^{-1}$ was selected as the possible tropopause.

Using the point of the possible tropopause, the average lapse rate between that point and all vertical levels within $2 \mathrm{~km}$ was calculated. In other words, a $2-\mathrm{km}$ vertical average, then a $1.9-\mathrm{km}$ average, then a $1.8-\mathrm{km}$ average, etc. was calculated. If all average lapse rates between the possible tropopause and $2 \mathrm{~km}$ above that point are less than $2 \mathrm{~K} \mathrm{~km}^{-1}$, that point is identified as the tropopause. If the criteria were not met, the process began again starting with the next occurrence of the local lapse rate that met the WMO criteria.

\section{2) SiMPLIFIED WMO}

First, the temperature lapse rate, $\Gamma=-\Delta T / \Delta z$, was calculated for every vertical level in the selected profile. The first altitude that had a local lapse rate less than $2 \mathrm{~K} \mathrm{~km}^{-1}$ was selected as the possible tropopause.

Then the 2-km vertical average lapse rate was calculated above the possible tropopause point. This was done by summing up the local lapse rate at every point $2 \mathrm{~km}$ above the evaluation point (the evaluation point and the 19 points above the evaluation point) then was divided by the number of points (in this case, 20 points).

If the local lapse rate and the $2-\mathrm{km}$ vertical average lapse rate above the point met were less than $2 \mathrm{~K} \mathrm{~km}^{-1}$, that point was defined as the tropopause. If the criteria were not met, the next point in the vertical profile would be evaluated.

\section{b. Potential vorticity}

First, potential vorticity was calculated at every point throughout the analysis domain using Ertel's potential vorticity theorem,

$$
\mathrm{PV}=\frac{1}{\rho}\left[\left(\frac{\partial v}{\partial x}-\frac{\partial u}{\partial y}\right)+f\right] \times \frac{\partial \theta}{\partial z},
$$

where $\rho$ is density, $v$ and $u$ are horizontal velocity, $f$ is Coriolis, and $\theta$ is potential temperature. In the calculations, it was assumed $\partial v / \partial x=\Delta v / \Delta x, \partial u / \partial y=\Delta u / \Delta y$, and $\partial \theta / \partial z=\Delta \theta / \Delta z$. Then using the conversion $1 \mathrm{PVU}=$ $10^{-6} \mathrm{~K} \mathrm{~kg}^{-1} \mathrm{~m}^{2} \mathrm{~s}^{-1}$, PV was converted to PVU.

At the time of initialization, a PVU threshold was chosen to represent the constant-altitude tropopause. In this study, the PVU threshold found to best fit the constant-altitude tropopause was 2.89 PVU.

\section{c. Static stability}

First, the static stability, $\partial \theta / \partial z=\Delta \theta / \Delta z$, was calculated for every vertical level for every relevant point in the 
domain. Similarly to the PV dynamical tropopause definition, a threshold value was chosen at the time of initialization to reflect the constant-altitude tropopause, $d \theta / d z=0.012 \mathrm{~K} \mathrm{~m}^{-1}$. The lowest altitude that was equivalent to or exceeded the chosen threshold was identified as the tropopause.

\section{d. Curvature of the Brunt-Väisälä frequency}

First, the square of BVF,

$$
N^{2}=\frac{g}{\theta} \frac{\partial \theta}{\partial z}=\frac{g}{\theta} \frac{\Delta \theta}{\Delta z},
$$

where $g$ is the gravitational constant, $\theta$ is potential temperature, and $z$ is the altitude, was calculated for each vertical level for every relevant point in the domain. Then the gradient of the BVF, or in this case the difference of the BVF with respect to height $(\mathrm{BVF}$ gradient $=\Delta N / \Delta z)$ was calculated for every height. The curvature of the BVF, or the difference of the $\mathrm{BVF}$ gradient with respect to height,

$$
\mathrm{BVF} \text { curvature }=\frac{(\Delta N / \Delta z)_{k+1}-(\Delta N / \Delta z)_{k}}{\Delta z},
$$

was then calculated. Finally, the altitude at which the maximum curvature was located was identified as the tropopause.

\section{e. Stratospheric tracer concentration}

First, a passive tracer was initialized in the stratosphere only (from $10.85 \mathrm{~km}$ to the model top) with a concentration of $1.0 \mathrm{~kg} \mathrm{~kg}^{-1}$. In this study, a threshold of $0.5 \mathrm{~kg} \mathrm{~kg}^{-1}$ was chosen to represent the tropopause. In other words, an altitude must contain at least $50 \%$ stratospheric air to be considered in the stratosphere. When evaluating a vertical column from the ground up, the first altitude at which the stratospheric tracer concentration was equivalent to or greater than the designated threshold was identified as the tropopause.

\section{REFERENCES}

Barber, K., 2015: Simulations of convectively-induced turbulence based on radar-based climatology of tropical storm types. M.S. thesis, Dept. of Atmospheric Sciences, University of North Dakota, 151 pp.

Bethan, S., G. Vaughan, and S. J. Reid, 1996: A comparison of ozone and thermal tropopause heights and the impact of tropopause definition on quantifying the ozone content of the troposphere. Quart. J. Roy. Meteor. Soc., 122, 929-944, https:// doi.org/10.1002/qj.49712253207.

Bigelbach, B. C., G. L. Mullendore, and M. Starzec, 2014: Differences in deep convective transport characteristics between quasiisolated strong convection and mesoscale convective systems using seasonal WRF simulations. J. Geophys. Res. Atmos., 119, 11445-11 455, https://doi.org/10.1002/2014JD021875.
Birner, T., 2010: Residual circulation and tropopause structure. J. Atmos. Sci., 67, 2582-2600, https://doi.org/10.1175/2010JAS3287.1.

Cooney, J. W., K. P. Bowman, C. R. Homeyer, and T. M. Fenske, 2018: Ten year analysis of tropopause-overshooting convection using GridRad data. J. Geophys. Res. Atmos., 123, 329343, https://doi.org/10.1002/2017JD027718.

Dickerson, R. R., and Coauthors, 1987: Thunderstorms: An important mechanism in the transport of air pollutants. Science, 235, 460-465, https://doi.org/10.1126/science.235.4787.460.

Durran, D. R., and J. B. Klemp, 1983: A compressible model for the simulation of moist mountain waves. Mon. Wea. Rev., 111, 2341-2361, https://doi.org/10.1175/1520-0493(1983)111<2341: ACMFTS $>2.0 . \mathrm{CO} ; 2$

Feichter, J., and P. J. Crutzen, 1990: Parameterization of vertical tracer transport due to deep cumulus convection in a global transport model and its evaluation with ${ }^{222}$ radon measurements. Tellus, 42B, 100-117, https://doi.org/10.1034/j.1600-0889.1990.00011.x.

Fischer, H., and Coauthors, 2003: Deep convective injection of boundary layer air into the lowermost stratosphere at midlatitudes. Atmos. Chem. Phys., 3, 739-745, https://doi.org/10.5194/ acp-3-739-2003.

Gettelman, A., P. Hoor, L. L. Pan, W. J. Randel, M. I. Hegglin, and T. Birner, 2011: The extratropical upper troposphere and lower stratosphere. Rev. Geophys., 49, RG3003, https://doi.org/ 10.1029/2011RG000355.

Hauf, T., P. Schulte, R. Alheit, and H. Schlager, 1995: Rapid vertical trace gas transport by an isolated midlatitude thunderstorm. J. Geophys. Res., 100, 22 957-22970, https://doi.org/ 10.1029/95JD02324.

Hoerling, M. P., T. D. Schaack, and A. J. Lenzen, 1991: Global objective tropopause analysis. Mon. Wea. Rev., 119, 1816-1831, https://doi.org/10.1175/1520-0493(1991)119<1816:GOTA >2.0.CO;2.

Holton, J. R., and G. J. Hakim, 2013: An Introduction to Dynamic Meteorology. 5th ed. Academic Press, 532 pp.

Homeyer, C. R., and Coauthors, 2014: Convective transport of water vapor into the lower stratosphere observed during doubletropopause events. J. Geophys. Res. Atmos., 119, 10 941-10 958, https://doi.org/10.1002/2014JD021485.

Kunz, A., P. Konopka, R. Müller, and L. L. Pan, 2011: Dynamic tropopause based on isentropic potential vorticity gradients. J. Geophys. Res., 116, D01110, https://doi.org/10.1029/2010JD014343.

Mullendore, G. L., D. R. Durran, and J. R. Holton, 2005: Crosstropopause tracer transport in midlatitude convection. J. Geophys. Res., 110, D06113, https://doi.org/10.1029/2004JD005059.

Pan, L. L., W. J. Randel, B. L. Gary, M. J. Mahoney, and E. J. Hintsa, 2004: Definitions and sharpness of the extratropical tropopause: A trace gas perspective. J. Geophys. Res., 109, D23103, https://doi.org/10.1029/2004JD004982.

Poulida, O., R. R. Dickerson, and A. Heymsfield, 1996: Stratosphere-troposphere exchange in a midlatitude mesoscale convective complex: 1. Observations. J. Geophys. Res., 101, 6823-6836, https://doi.org/10.1029/95JD03523.

Randel, W. J., D. J. Seidel, and L. L. Pan, 2007: Observational characteristics of double tropopauses. J. Geophys. Res., 112, D07309, https://doi.org/10.1029/2006JD007904.

Santer, B. D., and Coauthors, 2003: Contributions of anthropogenic and natural forcing to recent tropopause height changes. Science, 301, 479-483, https://doi.org/10.1126/ science. 1084123

Sharman, R. D., and J. M. Pearson, 2017: Prediction of energy dissipation rates for aviation turbulence. Part I: Forecasting nonconvective turbulence. J. Appl. Meteor. Climatol., 56, 317337, https://doi.org/10.1175/JAMC-D-16-0205.1. 
Skamarock, W. C., 2006: Positive-definite and monotonic limiters for unrestricted-time-step transport schemes. Mon. Wea. Rev., 134, 2241-2250, https://doi.org/10.1175/MWR3170.1.

- and Coauthors, 2000: Numerical simulations of the July 10 stratospheric-tropospheric experiment: Radiation, aerosols, and ozone/deep convection experiment convective system: Kinematics and transport. J. Geophys. Res., 105, $19973-$ 19 990, https://doi.org/10.1029/2000JD900179.

Towns, J., and Coauthors, 2014: XSEDE: Accelerating scientific discovery. Comput. Sci. Eng., 16, 62-74, https://doi.org/10.1109/MCSE.2014.80.

Twohy, C. H., and Coauthors, 2002: Deep convection as a source of new particles in the midlatitude upper troposphere. J. Geophys. Res., 107, 4560, https://doi.org/10.1029/2001JD000323.

Wales, P. A., and Coauthors, 2018: Stratospheric injection of brominated very short-lived substances: Aircraft observations in the western Pacific and representation in global models. J. Geophys. Res. Atmos., 123, 5690-5719, https://doi.org/10.1029/ 2017JD027978.

Weisman, M. L., and J. B. Klemp, 1982: The dependence of numerically simulated convective storms on vertical wind shear and buoyancy. Mon. Wea. Rev., 110, 504-520, https://doi.org/ 10.1175/1520-0493(1982)110<0504:TDONSC >2.0.CO;2.

WMO, 1957: Definition of the tropopause. WMO Bull., 6, 136.

Zahn, A., and C. A. M. Brenninkmeijer, 2003: New directions: A chemical tropopause defined. Atmos. Environ., 37, 439-440, https://doi.org/10.1016/S1352-2310(02)00901-9.

- — - and P. F. J. van Velthoven, 2004: Passenger aircraft project CARIBIC 1997-2002, part I: The extratropical chemical tropopause. Atmos. Chem. Phys. Discuss., 4, 10911117, https://doi.org/10.5194/acpd-4-1091-2004. 